\title{
Correction to: miRNA Profile and Bioinformatic Analysis for Diagnosis in Patients with Stage IIIA Colon Cancer
}

\section{Cigdem Gungormez $^{1}$ (D) $\cdot$ Emine Teker $^{2} \cdot$ Sema Atmanoglu $^{2} \cdot$ Ersin Borazan $^{3}$}

Published online: 9 November 2021

(c) Springer Science+Business Media, LLC, part of Springer Nature 2021

\section{Correction to: Biochemical Genetics https://doi.org/10.1007/s10528-021-10096-1}

The original version of this article unfortunately contained a mistake. The ethics committee number appears incorrectly in the article as ' $16 / 05 / 14$ ' but it should have been '2019/02/12'.

The original article has been corrected.

Publisher's Note Springer Nature remains neutral with regard to jurisdictional claims in published maps and institutional affiliations.

The original article can be found online at https://doi.org/10.1007/s10528-021-10096-1.

\section{Cigdem Gungormez}

gungormezcigdem@gmail.com

1 Department of Medical Biology, Faculty of Medicine, Siirt University, Siirt, Turkey

2 Biology Department, Faculty of Arts and Sciences, Harran University, Şanlıurfa, Turkey

3 General Surgery Department, Medical Faculty, Gaziantep University, Gaziantep, Turkey 